\title{
Ocena przydatności obiektywnych metod badania słuchu u dzieci i młodzieży z zespołem Downa - badania wstępne
}

\section{Evaluation of the usefulness of objective methods of hearing testing in children and adolescents with Down syndrome - preliminary study}

\author{
Katarzyna Sienkiewicz, Adam Piłka, Krzysztof Kochanek \\ Instytut Fizjologii i Patologii Słuchu, Światowe Centrum Słuchu, Warszawa/Kajetany \\ Adres autora: Katarzyna Sienkiewicz, Światowe Centrum Słuchu, ul. Mokra 17, Kajetany, 05-830 Nadarzyn, \\ e-mail: sienkiewicz_katarzyna@interia.pl
}

\section{Streszczenie}

Wstęp: Częstość występowania zespołu Downa (ZD) wśród żywo urodzonych noworodków wynosi 1 na 600-700. Jest to najczęstsza aberracja ludzkich chromosomów autosomalnych. Jedną z przyczyn opóźnień w rozwoju intelektualnym, poznawczym i językowym u dzieci z zespołem Downa są zaburzenia słuchu. Szacuje się, że odsetek występowania ubytków słuchu u dzieci z ZD wynosi od 38\% do $82 \%$. Wielu badaczy zgadza się, że najczęściej występującym rodzajem niedosłuchu jest niedosłuch przewodzeniowy, jednak inne źródła wskazują także na niedosłuch mieszany lub czuciowo-nerwowy.

Materiał i metody: W badaniach udział wzięło 12 osób z zespołem Downa w wieku od 9 miesięcy do 28 lat. U wszystkich osób wykonano otoskopię, tympanometrię, badanie emisji otoakustycznych oraz słuchowych potencjałów wywołanych pnia mózgu (ABR).

Wyniki: Analiza wyników obiektywnych badań słuchu wykazała, że w badanej grupie pacjentów występują różnego rodzaju zaburzenia słuchu. Łączna analiza wyników obiektywnych badań słuchu wykazała, że zaburzenia przewodzeniowe obecne były w 4 przypadkach (25\%).

\begin{abstract}
Wnioski: Wyniki badań pilotażowych u dzieci i młodzieży zespołem Downa potwierdziły możliwość wykorzystania metod obiektywnych w ocenie słuchu tej grupy dzieci bez potrzeby stosowania anestezji oraz wykazały, że w tej grupie osób najczęściej występują zaburzenia słuchu typu przewodzeniowego.
\end{abstract}

Słowa kluczowe: diagnostyka słuchu • zespół Downa $•$ ABR • emisje otoakustyczne • tympanometria

Abstract

Background: The incidence of Down Syndrome (DS) of live-born infants is 1 in 600-700. It is the most common human autosomal chromosome aberration. One of the reasons for delays in intellectual, cognitive and language development in children with Down syndrome are hearing impairments. It is estimated that the prevalence of hearing loss in children with Down syndrome is from $38 \%$ to $82 \%$. Many researchers agree that the most common type of hearing loss is the conductive hearing loss, however, other sources also point at the mixed or sensorineural hearing loss.

Material and methods: The preliminary study included 12 persons with Down Syndrome, at the age between 9 months and 28 years. Otoscopic examination, tympanometry, otoacoustic emissions and auditory brainstem evoked potentials ABR were performed on all subjects.

Results: The analysis of the results of objective hearing tests showed various types of hearing disorders in the examined group of patients. The analysis of overall results of the objective hearing testing indicated the presence of conductive hearing loss in 4 persons $(25 \%)$. 
Conclusions: The results of pilot studies in children and adolescents with Down syndrome confirmed that objective methods can be used for evaluation of hearing in this group of children without the need to apply anesthesia. It was also shown that the most common hearing loss in this group of subjects was of conductive type.

Key words: diagnosis of hearing loss $\bullet$ Down syndrome $\bullet$ ABR $\bullet$ otoacoustic emissions $\bullet$ tympanometry

\section{Wstęp}

Częstość urodzeń dzieci z zespołem Downa (ZD) szacuje się na 1 z 600-700 [1]. Jest to najczęstsza aberracja ludzkich chromosomów autosomalnych. Zaburzenie rozwojowe zwane zespołem Downa jest zespołem malformacyjnym powstałym w wyniku niekompletnej embriogenezy na skutek obecności dodatkowego 21 chromosomu autosomalnego (lub jego długich ramion) w kariotypie. Nadekspresja materiału genetycznego w wyniku potrojenia liczby genów powoduje wielopoziomowe zaburzenia metaboliczne, dymorfizm tkankowy, liczne wady narządów wewnętrznych oraz charakterystyczne cechy fenotypowe $\mathrm{z}$ różnym stopniem upośledzenia umysłowego [2]. Jedną z przyczyn opóźnień w rozwoju intelektualnym, poznawczym i językowym u dzieci z zespołem Downa są zaburzenia słuchu. Szacuje się, że częstość występowania ubytków słuchu u dzieci z ZD wynosi od $38 \%$ do $82 \%$ [3,4]. Wady twarzoczaszki oraz nieprawidłowy przebieg trąbek słuchowych u osób z zespołem Downa są przyczyną zwiększenia zachorowalności na zapalenie ucha środkowego, zapalenie gardła oraz zatok przynosowych. Wąski przewód słuchowy zewnętrzny może utrudniać uwidocznienie błony bębenkowej za pomocą standardowych wzierników [5,6]. Wielu badaczy zgadza się, że najczęściej występującym rodzajem niedosłuchu u dzieci z zespołem Downa jest niedosłuch przewodzeniowy, jednak inne źródła wskazują także na niedosłuch mieszany lub czuciowo-nerwowy [7-17]. Liczni autorzy stwierdzają, że niedosłuchy u dzieci z zespołem Downa są rezultatem zaburzeń zlokalizowanych w uchu środkowym [7-9,11-13]. Sugeruje się, że przyczynami ubytków słuchu u dzieci z zespołem Downa są: zagęszczona woskowina uszna, częste wysiękowe zapalenia ucha środkowego oraz nieprawidłowości wentylacyjne i mechaniczne ucha środkowego $[18,19]$. Wczesne zdiagnozowanie niedosłuchów u dzieci ma kluczowe znaczenie dla rozwoju języka [20,21].

Przez wiele lat ocena słuchu u osób z zespołem Downa była bardzo trudna lub wręcz niemożliwa. Wynikało to z ograniczonego dostępu do metod obiektywnych w diagnostyce zaburzeń słuchu oraz braku współpracy ze strony pacjentów z zespołem Downa.

$\mathrm{W}$ ostatnich latach pojawiło się w piśmiennictwie wiele prac dotyczących zaburzeń słuchu u dzieci z zespołem Downa, w których do oceny słuchu zastosowano metody elektrofizjologiczne [Kręcicki 2005; Roizen 1993; Pilecki 2002]. Kręcicki i wsp. (2005) objęli badaniami grupę 70 dzieci z zespołem Downa w wieku od 2 miesięcy do 17 lat. Wyniki badań wykazały znacząco skrócone interwały I-III u dzieci z zespołem Downa do $1 \mathrm{rż}$. w porównaniu $\mathrm{z}$ wynikami starszych dzieci z zespołem Downa oraz z grupą kontrolną. Latencja fali III oraz interwał I-III były znacząco dłuższe u starszych dzieci $\mathrm{z}$ zespołem Downa w porównaniu z grupą kontrolną [22].

Cechą nowoczesnych urządzeń do badań obiektywnych słuchu jest automatyzacja i obiektywizacja pomiarów, znaczne skrócenie czasu rejestracji oraz większa odporność na różnego rodzaju zakłócenia występujące podczas pomiarów. Niektóre urządzenia do rejestracji słuchowych potencjałów wywołanych umożliwiają obecnie przeprowadzenie badań nawet w przypadku aktywności motorycznej dziecka [25]. Niewątpliwie zwiększył się również dostęp do metod obiektywnych, co oznacza, że znacznie łatwiej można objąć tymi badaniami również dzieci z zespołem Downa.

Biorąc powyższe pod uwagę, można założyć, że dzięki zastosowaniu nowoczesnych urządzeń diagnostyka słuchu u dzieci z zespołem Downa będzie w wielu przypadkach możliwa bez potrzeby usypiania badanych środkami farmakologicznymi.

Celem pracy była ocena możliwości przeprowadzenia obiektywnych badań słuchu u osób z zespołem Downa bez zastosowania anestezji.

\section{Materiał i metody}

W badaniach udział wzięło 12 osób z zespołem Downa w wieku od 9 miesięcy do 28 lat ( 8 chłopców i 4 dziewczęta, wśród dzieci i młodzieży była jedna osoba dorosła 28 1.), warunkiem przystąpienia do badań było podpisanie zgody na przeprowadzenie testów przez opiekuna. Badania zostały wykonywane podczas snu fizjologicznego lub w stanie czuwania, w domu dziecka oraz w szkole specjalnej. Czas przeprowadzenia wszystkich badań zawierał się w przedziale od jednej do trzech godzin. Pacjenci nie byli poddawani wcześniejszym badaniom behawioralnym. Przed przystąpieniem do badań obiektywnych u każdego pacjenta wykonano otoskopię. Jeśli nie stwierdzono nieprawidłowości w obrębie przewodu słuchowego zewnętrznego oraz błony bębenkowej, wykonywano tympanometrię, badania emisji otoakustycznych oraz słuchowych potencjałów wywołanych pnia mózgu (ABR). Tympanometrię przeprowadzono za pomocą urządzenia OTOflex 100 firmy Otometrics. W badaniu tym zastosowano częstotliwość tonu $220 \mathrm{~Hz}$, a analizy tympanogramów dokonano na podstawie klasyfikacji Jergera [22]. Rejestrację sygnałów otoemisji dla trzasku - TEOAE wykonano za pomocą systemu ILO 6 (Otodynamics Ltd., Londyn). Badanie słuchowych potencjałów wywołanych pnia mózgu dla trzasku przeprowadzono za pomocą urządzenia Integrity V500 firmy Vivosonic. Pasmo wzmacniacza biologicznego zawierało się w przedziale od $30 \mathrm{~Hz}$ do $3000 \mathrm{~Hz}$. Badanie wykonywano procedurą szeregu natężeniowego, ze skokiem $10 \mathrm{~dB}$, rozpoczynając od natężenia $80 \mathrm{~dB}$ nHL. Jeżeli było to możliwe, w odpowiedziach ABR poza progiem fali $V$ wyznaczano również wartości interwałów czasowych. Kryterium normy progu słyszenia dla odpowiedzi ABR wynosiło $20 \mathrm{~dB}$ nHL.

\section{Wyniki}

W tabeli 1 przedstawiono wyniki badań obiektywnych słuchu wszystkich osób badanych. Tympanogram typu A uzyskano 
Tabela 1. Wyniki obiektywnych badań słuchu

Table 1. Results of objective hearing tests

\begin{tabular}{|c|c|c|c|c|c|c|c|}
\hline \multirow{2}{*}{ Nr pacjenta } & \multirow{2}{*}{$\begin{array}{c}\text { Wiek } \\
\text { pacjenta }\end{array}$} & \multicolumn{2}{|c|}{$\begin{array}{c}\text { Typ } \\
\text { tympanogramu }\end{array}$} & \multicolumn{2}{|c|}{$\begin{array}{c}\text { Obecność sygnału emisji } \\
\text { otoakustycznej TEOAE }\end{array}$} & \multicolumn{2}{|c|}{$\begin{array}{l}\text { Wartoś́́ progu } \\
\text { fali V [dB] }\end{array}$} \\
\hline & & UP & UL & UP & UL & UP & UL \\
\hline 1 & 2 lata i 8 m-cy & A & A & + & + & 20 & 20 \\
\hline 2 & 6 lat & A & A & + & - & 20 & 20 \\
\hline 3 & 28 lat & A & $\mathrm{C}$ & + & + & 20 & 30 \\
\hline 4 & 4 lata i 8 m-cy & A & A & + & + & 10 & 10 \\
\hline 5 & 6 lat & B (dren) & B (dren) & - & - & 20 & 20 \\
\hline 6 & 10 lat & C & C & + & + & 20 & 30 \\
\hline 7 & 9 lat & A & A & + & + & 20 & 20 \\
\hline 8 & 14 lat & $\mathrm{C}$ & B & - & - & 30 & 60 \\
\hline 9 & 12 lat & A & A & + & + & 20 & 20 \\
\hline 10 & 2 lata i 8 m-cy & $\mathrm{C}$ & $\mathrm{C}$ & - & - & 30 & 30 \\
\hline 11 & 5 lat & A & A & + & - & 20 & 20 \\
\hline 12 & 9 m-cy & A & A & - & - & 20 & 40 \\
\hline
\end{tabular}

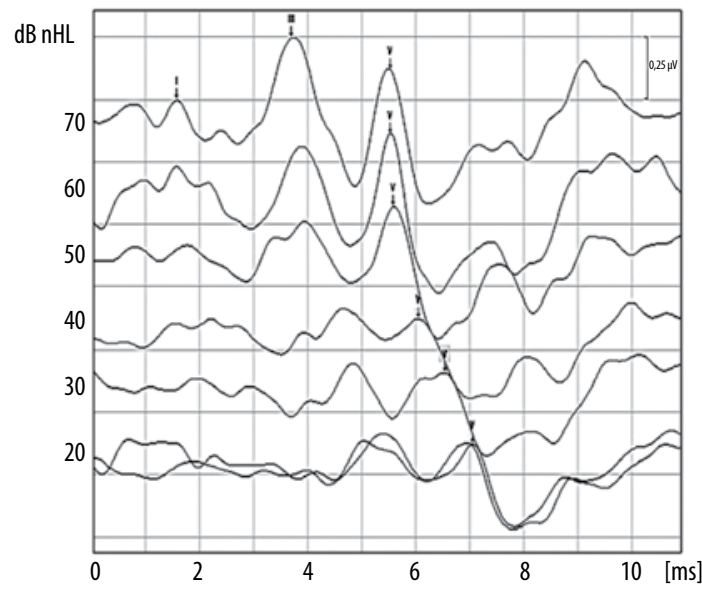

Rycina 1. Zapis rejestracji odpowiedzi ABR w uchu lewym u pacjenta $\mathrm{nr} 1$

Figure 1. ABR recordings in left ear of patient No. 1

w 15 uszach (62\%), tympanogram typu C w 6 uszach (25\%), a w jednym uchu otrzymano tympanogram typu B (4\%). Łącznie nieprawidłowe tympanogramy uzyskano w $29 \%$ uszu. U jednego badanego dziecka nie wykonano tympanometrii z uwagi na obecność drenu wentylacyjnego. W badaniu emisji otoakustycznej otrzymano 4 nieprawidłowe wyniki w uchu prawym (16\%) oraz $6 \mathrm{w}$ uchu lewym (25\%). W sumie brak otoemisji stwierdzono w $41 \%$ uszu.

Podwyższone wartości progów fali V (powyżej $20 \mathrm{~dB}$ nHL) w badaniu ABR stwierdzono w 7 uszach (29\%). W dwóch przypadkach podwyższenie progu fali $\mathrm{V}$ zaobserwowano w obojgu uszach, natomiast u 3 dzieci zwiększone wartości występowały tylko w jednym uchu. Na szczególną uwagę zasługuje pacjent nr 8, u którego w uchu lewym wartość progu fali $\mathrm{V}$ wynosiła $60 \mathrm{~dB} \mathrm{nHL}$. U tego pacjenta wynik badania tympanometrii w uchu lewym wskazywał

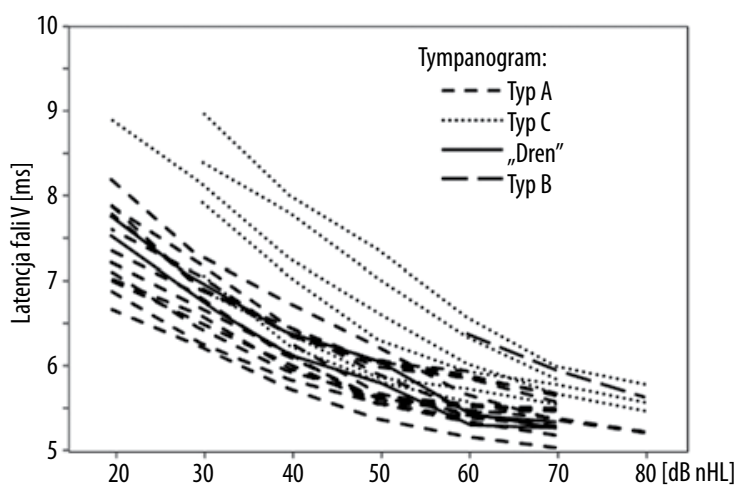

Rycina 2. Indywidualne wykresy funkcji latencja-natężenie dla różnych typów tympanogramów

Figure 2. Individual latency-intensity functions for different types of tympanograms

na podejrzenie zapalenia ucha środkowego (tympanogram typu B). Na rycinie 1 przedstawiono przykład rejestracji odpowiedzi ABR w uchu lewym u pacjenta nr 1. Uzyskane zapisy odpowiedzi cechuje wysoka jakość, wynikająca $\mathrm{z}$ metod pomiaru oraz jakości urządzenia. Zbliżoną jakość zapisów ABR uzyskano w większości przypadków.

Na rycinie 2 przedstawiono indywidualne wykresy funkcji latencja-natężenie dla fali V. Dla tympanogramów typu B i C wykresy są przesunięte wzdłuż osi natężeń w stosunku do krzywych dla osób z prawidłowymi tympanogramami, co jest charakterystyczne dla przewodzeniowych zaburzeń słuchu. Dla każdej intensywności trzasku wartości latencji fali V dla osób z tympanogramami B i C były znacznie dłuższe $\mathrm{w}$ porównaniu $\mathrm{z}$ wartościami latencji $\mathrm{w}$ grupie osób z prawidłowym tympanogramem. 


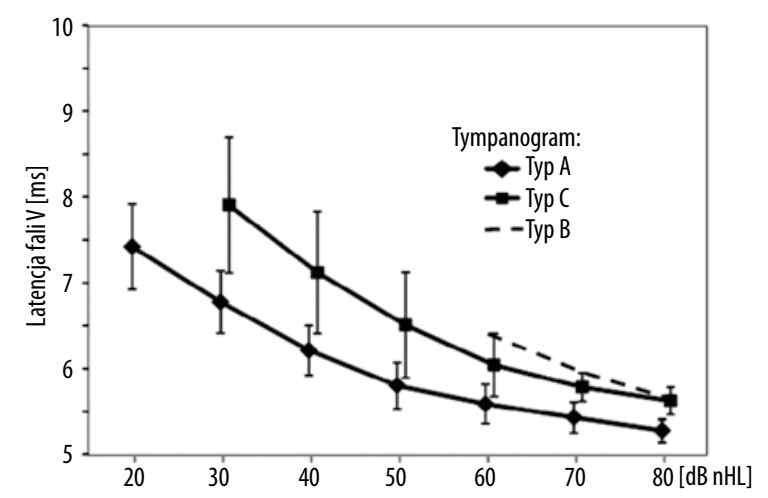

Rycina 3. Średnie wartości oraz odchylenie standardowe wartości latencji fali $\vee$ wyznaczone w uszach dla tympanogramu typu A oraz dla tympanogramu typu C. Wykres latencji w uchu z tympanogramem typu B zaznaczono linią przerywaną

Figure 3. Mean values and standard deviations of wave $V$ latency in the ears with tympanograms type A (diamonds) and tympanograms type $C$ (squares). The latency in the ear with tympanogram type $B$ is plotted with dashed line without markers

Na rycinie 3 przedstawiono wykresy średnich wartości latencji fali V w funkcji natężenia trzasku. Dla tympanogramów typu C i B wykres funkcji latencja-natężenie miał charakterystyczny przebieg jak dla niedosłuchów typu przewodzeniowego. Funkcję latencja-natężenie o przebiegu charakterystycznym dla niedosłuchu przewodzeniowego stwierdzono w 6 uszach (25\%). Porównanie średnich wartości latencji fali $\mathrm{V}$ dla poszczególnych intensywności trzasku wykazało istotne statystycznie ich zwiększenie dla uszu z tympanogramami typu B i C.

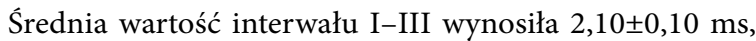
natomiast interwału III-V $-1,86 \pm 0,08 \mathrm{~ms}$. U wszystkich osób wartości interwałów czasowych I-III oraz III-V były w normie.

Łączna analiza wyników poszczególnych typów badań wykazała, że w 6 uszach (25\%) występują zaburzenia przewodzeniowe, a w jednym uchu zaburzenie słuchu typu odbiorczego.

\section{Dyskusja}

Ze względu na liczne problemy wynikające $\mathrm{z}$ wad anatomicznych, zwężenia jamy nosowo-gardłowej, przerostu migdałków gardłowych, dysfunkcji trąbek Eustachiusza $[27,28]$, dzieci i młodzież z zespołem Downa stanowią grupę o podwyższonym ryzyku wystąpienia niedosłuchów. Większość badań metodą ABR u tych dzieci wykonywana

\section{Piśmiennictwo:}

1. Cunningham C. Dzieci z zespołem Downa. Wyd. Warszawa: WSiP; 1994. jest w narkozie płytkiej, znacznie rzadziej podczas snu fizjologicznego czy w stanie czuwania. Podczas badań pilotażowych opiekunowie dzieci zgłaszali liczne, wcześniejsze problemy z wykonaniem badań w placówkach medycznych. Brak współpracy ze strony pacjenta często skutkował niewykonaniem badania, co powodowało konieczność ponownych wizyt w pracowniach diagnostycznych. W ten sposób znacznie wydłużał się czas rozpoznania zaburzeń słuchu oraz rozpoczęcia właściwej terapii.

Badania różnych autorów pokazują, że częstość występowania wad serca u dzieci $\mathrm{z}$ zespołem Downa wynosi od 7\% do 70\% [29-31]. Dlatego też bardzo często rodzice czy opiekunowie tych dzieci nie decydują się - pomimo podejrzenia niedosłuchu - na przeprowadzenie u nich badań $A B R$ w narkozie. Alternatywą dla badań $A B R$ we śnie indukowanym farmakologicznie są badania w warunkach optymalnych dla dziecka, takich jak dom lub szkoła, przeprowadzane podczas dziennej aktywności.

Zasadniczym celem pracy było sprawdzenie, czy u dzieci i młodzieży z zespołem Downa jest możliwe wykonanie obiektywnych badań słuchu, a w szczególności słuchowych potencjałów wywołanych pnia mózgu, bez potrzeby usypiania na drodze farmakologicznej. Badania wykonano na terenie szkoły specjalnej lub w domu dziecka, podczas snu fizjologicznego lub w stanie czuwania.

Wyniki uzyskane w niniejszej pracy wykazały, że badanie ABR można wykonać bez konieczności stosowania anestezji zarówno u niemowląt, jak i u dzieci starszych i młodzieży z zespołem Downa. Jakość zapisów ABR umożliwiała wyznaczenie latencji i progu fali $\mathrm{V}$ oraz interwałów czasowych i funkcji latencja-natężenie. Zaburzenia przewodzeniowe stwierdzono u 4 dzieci (33\%), natomiast tylko $\mathrm{w}$ jednym uchu stwierdzono zaburzenia słuchu typu odbiorczego niewielkiego stopnia. W większości przypadków występował tympanogram typu C, co wskazuje, że zasadniczą przyczyną zaburzeń przewodzeniowych w grupie dzieci objętych badaniami była dysfunkcja trąbki słuchowej. Wyniki uzyskane w niniejszej pracy potwierdzają zatem obserwacje innych autorów (Hassman i wsp. 1988; Balkany i wsp. 1979), dotyczące wysokiego odsetka zaburzeń przewodzeniowych w tej grupie pacjentów.

\section{Wnioski}

Na podstawie otrzymanych wyników sformułowano następujące wnioski:

1. U dzieci i młodzieży z zespołem Downa dominują zaburzenia słuchu typu przewodzeniowego.

2. Możliwe jest wykonanie badań obiektywnych słuchu u dzieci i młodzieży z zespołem Downa bez potrzeby stosowania anestezji dzięki użyciu urządzeń wysokiej jakości.

3. Przeprowadzone badania są badaniami pilotażowymi.
2. Korenberg JR, Chen XN, Schipper R, Sun Z, Gonsky R, Gerwehr $S$ i wsp. Down syndrome phenotypes: The consequences of chromosomal imbalance. Proc Nati Acad Sci USA, 1994; 91(11): 4997-5001. 
3. Keiser H, Montague J, Wold D, Maune D, Pattison D. Hearing loss of Down syndrome adults. Am J Ment Defic. 1981; 85: $467-72$.

4. Szyfter W, Łączkowska-Przybylska J. Hearing impairment in children with Down's syndrome. Otolaryngol Pol, 1999; 13: 83-6.

5. Cooley WC, Graham JM Jr. Down syndrome - an update and review for the primary pediatrician. Clin Pediat (Phila), 1991: 230-3.

6. Korniszewski L. Opieka nad dzieckiem z zespołem Downa. Medipress Pediatria, 1995.

7. Hassman E, Skotnicka B, Midro A, Musiatowicz M. Disortion products otoacustic emissions in diagnosis of hearing loss in Down syndrome. Int J Pediatr Otorhinolaryngol, 1988, 45: 199-206.

8. Davis B. Auditory disorders in Down's syndrome. Scan Audiol Suppl, 1998; 30: 65-8.

9. Iino Y, Imamura Y, Harigi S, Tanaka Y. Efficacy of tymanostomy tube insertion for ototis media with effusion in children with Down syndrome. Int J Pediatr Otorhinolaryngol, 1999, 49: 143-9.

10. Kaga K, Marsh R. Auditory brainstem responses in young children with Down's syndrome. Int J Pediatr Otolaryngol, 1986; 11: 29-38.

11. Murizi M, Ottaviani F, Paludetti G, Lungarotti S. Audiological findings in Down's children. Int J Pediatr Otolaryngol, 1985; 9: 227-32.

12. Pappas DG, Flexer C, Shackelford MA. Otological and habilitativ management of children with Down syndrome. Laryngoscope, 1994; 104: 1065-70.

13. Roizen JR, Wolters C, Nicol T, Blondis TA. Hearing loss in children with Down syndrome. J Pediatr, 1993; 123: 10-12.

14. Shott SR, Joseph A, Heithaus D. Hearing loss in children with Down syndrome. Int Pediatr Otorhinolaryngol, 2001; 61: 199-205.

15. Squires N, Aine C, Buchwald J, Norman R, Galbraith G. Auditory brainstem responses abnormalities in severely and profoundly retarded adults. Electroencephalogr Clin Neurophysiol, 1980; 50: 172-85.

16. Ferii R, Del Gracco S, Elia M, Musumeci SA, Stefani MC. Age, sex and mental retardation related changes of brainstem auditory evoked potentials in Down's syndrome. Ital J Neurol Sci, 1995; 16: 377-83.

17. Folsom RC, Widen JE, Wilson WR. Auditory brainstem responses in infants with Down's syndrome. Arch Otolaryngol, 1983; 109: 607-10.
18. Balkany TJ, Mischake RE, Downs MP, Jafek BW. Ossicular abnormalities in Down's syndrome. Otolaryngol Head Neck Surg, 1979; 87: 372-84.

19. McPherson B, Lai SP, Leung KK. Hearing loss in Chinese school children with Down syndrome. Int J Pediatr Otorhinolaryngol, 2007; 71: 1905-15.

20. Poblano A, Munoz-Hernandez SE, Arias-Arandal I, Castro Cue-De Carpizo L i wsp. Brainstem auditory evoked potentials and median latency in children with Down's syndrome. Bol Med Hosp Infant Mex, 1991; 48: 793-9.

21. Steffens ML, Oller DK, Lynch M, Urbano RC. Vocal development in infants with Down's syndrome and infants who are developing normally. Am J Ment Retard, 1992; 97: 235-46.

22. Kręcicki T, Zalesska-Kręcicka M, Kubiak K, Gawron W. Brain auditory evoked potentials in children with Down syndrome. Int J Pediatr Otorhinolaryngol, 2005; 69: 615-20.

23. Roizen JR, Wolters C, Nicol T, Blondis TA. Hearing loss in children with Down syndrome. J Pediatr, 1993; 123: 10-2.

24. Pilecki W, Sadowska L, Mysłek M, Śliwiński Z. Efektywność wczesnej neurostymulacji rozwoju wg Wrocławskiego Modelu Usprawniania dzieci z zespołem Downa w świetle badań bioelektrycznych mózgu. Fizjoterapia Polska, 2002; 2: 99-107.

25. Piłka A, Kochanek K, Skarżyński H, Skarżyński PH, Bruski Ł. Ocena efektywności algorytmów do usuwania artefaktów mięśniowych z zapisów ABR zastosowanych w urządzeniu Vivosonic Integrity. Konferencja Naukowo-Szkoleniowa, XVII Dni Otolaryngologii Dziecięcej. Mikołajki, 9-11 czerwca 2011.

26. Jerger JF. Clinical experience with impedance audiometry. Arch Otolaryngol, 1970; 92: 311-24.

27. Brown PM, Lewis GTR, Parker AJ, Maw AR. The skull base and nasopharynx in Down's syndrome in relation to hearing impairment. Clin Otolaryngol, 1989; 14: 241-6.

28. Jacobs IN, Gray RF, Todd NW. Upper airway obstruction in children with Down syndrome. Arch Otolaryngol Head Neck Surg, 1996; 122: 945-50.

29. Berg JM, Crome L, France NE. Congenital septal defect in mongolism. Br Heart J, 1960; 22: 331-46.

30. Evans PR. Cardiac anomalies in mongolism. British, 1950; 12: 258-62.

31. Liu MC, Corlett K. A study of congenital heart defects in mongolism. Archives of disease in child within Down's syndrome and congenital heart disease. Hood, 1959; 34: 410-9.

32. Balkany TJ, Mischake RE, Downs MP, Jafek BW. Hearing loss in Down syndrome. A treateable handicap more Combom than generally recognized. Clin Pediatr, 1979; 18: 116-8. 